\title{
A Comparative in vitro Evaluation of Vertical Root Fracture Resistance of Endodontically Treated Teeth using Different Obturating Materials
}

\author{
${ }^{1}$ Roopak Bose Carlos, ${ }^{2}$ Suman Makam, ${ }^{3}$ Vamsi Kalyan Yaragonda, ${ }^{4} \mathrm{H}$ Murali, ${ }^{5}$ Anukriti Tyagi, ${ }^{6}$ Rajani Rose
}

\begin{abstract}
Aim: To compare the vertical root fracture resistance of endodontically treated teeth obturated using different obturating materials.

Materials and methods: Decoronated roots of 75 single canal lower second premolar teeth were divided randomly into 5 groups. The first group (Group I) served as a negative control. The remaining four Groups were cleaned and shaped using ProTaper Endodontic rotary files and obturated with guttapercha + TubliSeal EWT sealer (Group II), ThermaFil + AH Plus sealer (Group III), RealSeal + RealSeal sealer (Group IV) and GuttaFlow obturating system (Group V). The roots were then embedded in acrylic resin blocks and subjected to vertical load until fracture with a spreader in a universal testing machine and the forces were recorded.
\end{abstract}

Results: Fracture resistance of group I>group IV > group $V>$ group III > group II, which were statistically significant.

Conclusion: Obturation of roots with resin based obturation material-RealSeal had increased VRF resistance compared to the gutta-percha obturation systems.

Clinical significance: Obturation of the root canals with resin based obturation system-Resilon reinforces the fracture resistance of endodontically treated teeth and contributes to the overall success of the endodontic treatment.

Keywords: Vertical root fracture, Resilon, ThermaFil, Gutta flow, Gutta-percha.

\footnotetext{
${ }^{1}$ Senior Lecturer, ${ }^{2,4}$ Professor, ${ }^{3}$ Consultant Endodontist, ${ }^{5,6}$ Private Practitioner

${ }^{1}$ Department of Conservative Dentistry and Endodontics, Vydehi Institute of Dental Sciences and Research Centre, Bengaluru Karnataka, India

${ }^{2}$ Department of Conservative Dentistry and Endodontics College of Dental Sciences and Research Centre, Ahmedabad Gujarat, India

${ }^{3}$ Department of Conservative Dentistry and Endodontics, Dental Care Centre, Bengaluru, Karnataka, India

${ }^{4}$ Department of Conservative Dentistry and Endodontics DAPMRV Dental College and Hospital, Bengaluru, Karnataka India

${ }^{5}$ Mumbai, Maharashtra, India

${ }^{6}$ Dental Solutions, Bengaluru, Karnataka, India
}

Corresponding Author: Roopak Bose Carlos, Senior Lecturer Department of Conservative Dentistry and Endodontics, Vydehi Institute of Dental Sciences and Research Centre, \#82 EPIP Area Whitefield, Bengaluru-560066, Karnataka, India, Phone: +919742387246, Fax: 080-28416199, e-mail: carlosroop@gmail.com
How to cite this article: Carlos RB, Makam S, Yaragonda VK, Murali $\mathrm{H}$, Tyagi A, Rose R. A Comparative in vitro Evaluation of Vertical Root Fracture Resistance of Endodontically Treated Teeth using Different Obturating Materials. World J Dent 2014;5(2):113-117.

\section{Source of support: Nil}

Conflict of interest: None

Acronyms and abbreviations: VRF: Vertical root fracture; ANOVA: Analysis of variance.

\section{INTRODUCTION}

Vertical root fracture (VRF) is a longitudinally oriented fracture of the root extending from the root canal to the periodontium that may begin in the crown, root apex, or any point in between. ${ }^{1}$ It is a frustrating complication, presenting a clinical problem which is difficult to diagnose and treat. The incidence of VRF is more in teeth after endodontic therapy. ${ }^{2}$ Survival rate studies show vertical root fracture as one of the reasons to extract endodontically treated teeth. ${ }^{3,4}$

The factors predisposing endodontically treated teeth to VRF are caries removal, access preparation, canal instrumentation, dehydrating effects of irrigants, long time exposure to calcium hydroxide, excessive pressure during obturation, preparation for the final restoration and loss of proprioception. ${ }^{5-10}$ It is speculated that VRFs begin during the canal instrumentation and filling, and progress to more extensive fractures with time and under occlusal stress. ${ }^{11-14}$ It is a serious clinical concern with unfavorable prognosis resulting mostly in the extraction of teeth or the resection of the affected root. ${ }^{11,12,15}$

Restoring the endodontically treated teeth with crown reduces the incidence of VRFs, however, in some cases even properly restored teeth fracture. Therefore, one of the main aims of filling the root canals must be to reinforce the root canal dentin so as to increase the fracture resistance. Although gutta-percha has served as the gold standard of root canal fillings, it does not represent the universal ideal when reinforcement of endodontically treated teeth is concerned. Recently many alternatives have been introduced for root filling, claiming to provide apical seal and ability to reinforce of the tooth.

The aim of this study was to evaluate the vertical root fracture resistance of endodontically treated teeth obturated 
with different obturating materials, using the universal testing machine. The null hypothesis was that there are no differences in vertical fracture resistance between different obturating materials.

\section{MATERIALS AND METHODS}

Seventy-five single canal extracted human lower second premolar teeth were collected and stored in physiological saline. Teeth with immature apices, root caries, root fractures, cracks, dilacerations, canal calcifications and root canal treated teeth were excluded from the study.

The teeth were decoronated at $12 \mathrm{~mm}$ from the anatomical root tip using diamond disks and roots were randomly allocated into five groups of fifteen each. The first group served as a negative control (Group I); roots were not instrumented or obturated. In the remaining four groups, the patency of the canals were established and the working length was determined by introducing a size 10 file into the canal until it exited from the apex. This length was measured, and the working length was set $1 \mathrm{~mm}$ short of this length. The roots were then cleaned and shaped using ProTaper endodontic rotary files. The canals were irrigated with $1 \mathrm{ml}$ each of $2.5 \%$ sodium hypochlorite and $17 \%$ EDTA between each file. The canals were shaped to size F3 ProTaper rotary endodontic file. The prepared specimens received a final flush with $2 \mathrm{ml}$ of $2.5 \%$ sodium hypochlorite followed by $2 \mathrm{ml}$ of $17 \%$ EDTA. Root canals were then dried with paper points.

\section{Obturation of the Root Canals}

The root samples in the second group II were obturated by cold lateral condensation technique with gutta-percha and TubliSeal EWT sealer (Sybron Endo, Orange, CA), zinc oxide eugenol based sealer, using a finger spreader of size 25. In the third group (Group III), the roots were obturated using the plastic carrier ThermaFil (Dentsply, Maillefer, Switzerland) and AH plus (Dentsply, De Trey) as a sealer. The fourth group (Group IV), received a root filling by lateral condensation using RealSeal points and RealSeal sealer (Sybron Endo, Orange, CA); a resin based material. The fifth group (Group V) received a root filling using a single cone gutta-percha master cone and GuttaFlow sealer (Coltene/ Whaledent). Excess obturating material was removed with a heated hand instrument. All the roots were kept at $37^{\circ} \mathrm{C}$ with $100 \%$ humidity for at least 72 hours to allow the sealers to set completely.

\section{Preparation for Mechanical Testing}

A cold cure acrylic resin block of $15 \times 15 \times 25 \mathrm{~mm}$ was fabricated. A mold of the resin block was made with addition silicone rubber base material. Cold cure acrylic resin was poured into the mold and then the roots were vertically embedded - till the coronal margin, keeping the cut face and the canal orifice exposed. The blocks were allowed to set for 24 hours.

The blocks were then mounted onto the lower jaw of the Universal testing machine. A size 40 stainless steel finger spreader directed onto the canal orifice was attached to the upper jaw of the universal testing machine. It was calibrated to vertically drive the spreader into the root canal at a speed of $10 \mathrm{~mm} / \mathrm{min}$ and allowed to penetrate the root canal filling until the root fractured (Fig. 1). The force applied to the root canal via the spreader was recorded in the form of a (Graph 1 ). The fracture was defined as a point at which a drop in force was observed. The amount of force required for fracture was recorded for each root.

\section{RESULTS}

The fracture resistance of the root samples were tabulated and subjected to statistical analysis using ANOVA and Bonferroni test (Table 1). There was a statistically significant difference among the five groups with respect to the mean force required for the fracture of the roots $(p<0.001)$. The control group showed the highest resistance to VRF than any other test group. Among the instrumented and obturated samples, the highest resistance to VRF was recorded in group IV followed by groups V, III and II respectively (see Table 1). There was statistically significant difference between each group, except between groups III and II (see Table 1). Thus, among the obturated groups, the root samples obturated with Resilon showed the highest resistance to fracture.

Table 1: The mean vertical root fractures among various groups

\begin{tabular}{llllllll}
\hline Groups & $n$ & Mean & Std. dev. & Min. & Max. & $F$ & $p$-value \\
\hline Group I & 15 & 226.37 & 20.58 & 200 & 257.8 & & \\
Group II & 15 & 49.34 & 16.92 & 25.9 & 75.6 & & \\
Group III & 15 & 54.17 & 14.9 & 34.6 & 72.5 & 134.668 & $<0.001^{*}$ \\
Group IV & 15 & 165.12 & 31.43 & 107 & 208.6 & & \\
Group V & 15 & 98.33 & 36.08 & 43 & 162.6 & & \\
\hline
\end{tabular}




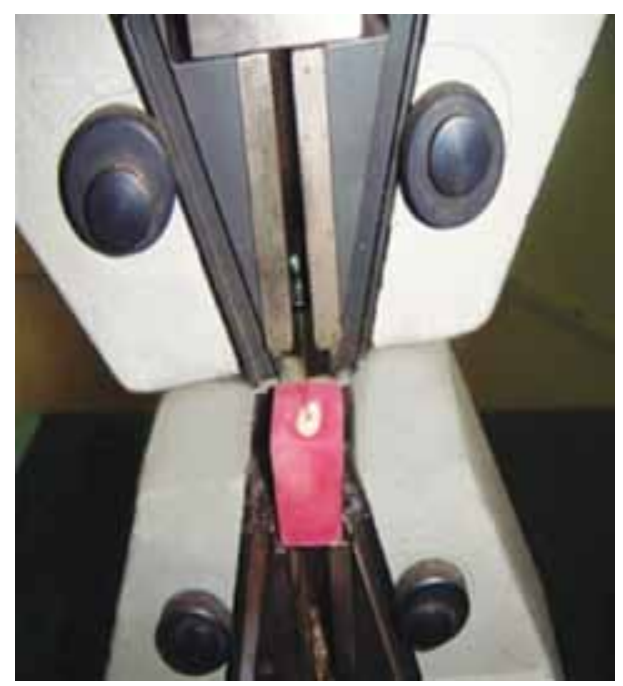

Fig. 1: Finger spreader inserted into the obturated root canal using universal testing machine

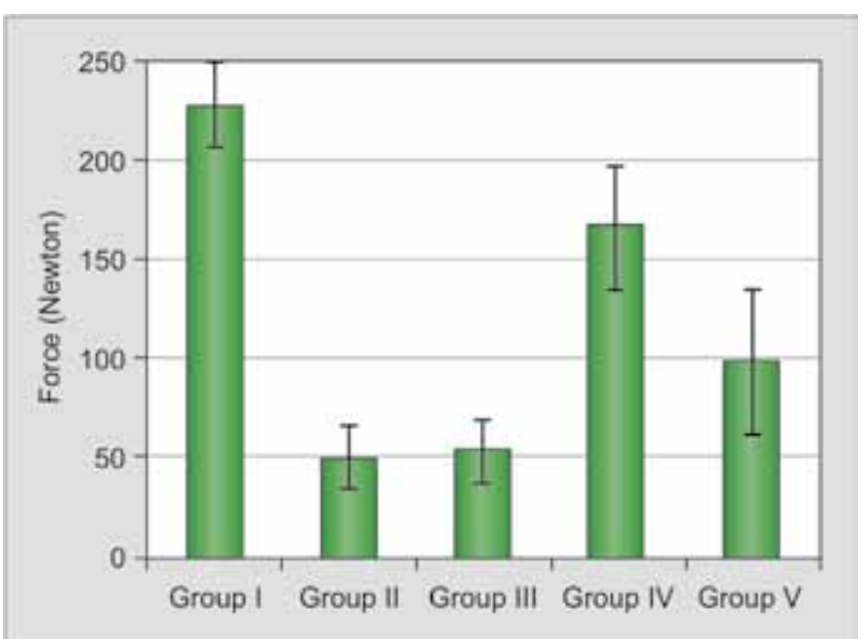

Graph 1: The mean vertical root fracture among various groups

\section{DISCUSSION}

Root canal therapy invariably leads to weakening of the tooth. Access cavity preparation and cleaning and shaping of the canals account for almost $30 \%$ reduction in the VRF resistance. ${ }^{9,16}$ The likelihood for fracture increases when the wedging forces of the spreader are added during the lateral condensation or when excessive dentin is removed to facilitate placement of final restoration. ${ }^{9,12,17,18}$ It has been speculated that some vertical root fractures begin during canal instrumentation and filling, and progress to more extensive fractures with time and occlusal stress. ${ }^{11,19}$

In the past many attempts have been made to reinforce an endodontically treated root by using different obturating materials. ${ }^{5,9,20}$ Adhesive sealers based on both resin and glass ionomer have shown to be ineffective in increasing the VRF and mechanical properties of the endodontically treated roots. ${ }^{5,30}$ On the contrary, studies have shown that adhesive resin based obturation systems increased the VRF resistance of the instrumented roots compared to gutta-percha based systems. ${ }^{28,29}$ Hence in the present study, the VRF resistance of the roots obturated with different gutta-percha obturation systems and techniques were compared with those obturated with adhesive resin based obturation system-RealSeal.

In the present study single canal extracted human second premolars were collected and decoronated at $12 \mathrm{~mm}$ from the anatomical root tip. Roots with similar buccolingual dimensions were selected to eliminate variations in dimensions. Premolars were selected as they have high prevalence in VRFs. ${ }^{16,21}$ Decoronating the tooth samples also eliminate the variable of access cavity preparation.

Cleaning and shaping of the root canals of the samples was done with rotary ProTaper endodontic files with $2.5 \%$ sodium hypochlorite as irrigant during preparation of the canals. The final flush of the canals was done with $17 \%$ EDTA and $2.5 \%$ sodium hypochlorite used alternatively, concluding with EDTA, as any remaining sodium hypochlorite might inhibit the setting of the resin materials.

The test samples were embedded in acrylic resin blocks to simulate the support given to healthy teeth by the alveolar bone and to reduce stresses caused by unrealistic bending movements. Fracture resistances of the roots were evaluated using the universal testing machine. The force was generated into the obturated canal by means of a spreader vertically directed along the long axis of the tooth. ${ }^{13,22,23}$ This was chosen because it provides force distribution from within the root canal wall and fractures occurred as a result of forces transmitted via the obturating material. It resembles root fractures caused of endodontic origin or from a post. The force was directed at an angle of $0^{\circ}$, resulting in primarily a splitting stress applied above the access opening. ${ }^{5}$ Stresses generated from inside the root canal were transmitted through the root to the surface where the interdentin bonding failed. ${ }^{24}$ The test terminated after a 25\% drop in the maximum force recorded or when an audible crack was heard.

In the present study VRF of roots obturated with Resilon, GuttaFlow, ThermaFil + AH Plus sealer, and gutta-percha + TubliSeal EWT sealer were compared with control (uninstrumented and unobturated canals). Results show that none of the roots in the test groups regained their original fracture resistance. Among obturation systems the fracture resistance was in the following order - Resilon $>$ GuttaFlow $>$ ThermaFil + AH Plus $>$ gutta-percha + TubliSeal EWT. The resin based obturating system performed better than the gutta-percha based obturating systems.

Adhesion and mechanical interlocking of the sealer with the root canal dentin prevents microleakage and decreases the risk of fracture. ${ }^{26,27}$ In the present study the only adhesive system tested was Resilon obturating material, which 
showed the highest fracture resistance among the test groups. The results agree with previous studies which emphasized the reinforcing effect of Resilon on the roots. ${ }^{28,29}$ This could be due to the 'Monoblock' effect where the Resilon core, sealer and the dentin tubules become a single solid structure by means of adhesion which significantly increases the resistance to fracture. ${ }^{26,28}$

Among the test groups obturated with cold lateral condensation, the gutta-percha based obturation system showed the least and the resin based obturation system showed highest VRF resistance. The use of resin adhesive based obturation systems like Resilon seems to overcome the stresses generated during the cold lateral condensation technique. This lays further emphasizes on the use of adhesive systems in obturating the root canals to achieve better fracture resistance.

Among the gutta-percha based systems, GuttaFlow group achieved higher fracture resistance. It could be due to the minimal stress produced during the obturation. ThermaFil obturated root samples were significantly weaker than the GuttaFlow obturated roots, in spite of being a less stress producing single cone obturating system. In the GuttaFlow system, the interface between the sealer and the master cone gutta-percha is eliminated and its increased adaptability and sealing ability, ${ }^{25}$ may be the cause for its higher fracture resistance.

Under the limitations of the present study, it can be concluded that:

The control group, with uninstrumented and unobturated roots showed the highest VRF resistance compared to the test groups.

Roots obturated by the resin based obturating material had the highest VRF resistance among the test groups.

GuttaFlow obturated roots had the highest VRF resistance among the roots obturated with gutta-percha based materials.

Roots obturated with gutta-percha + TubliSeal EWT sealer using cold lateral condensation showed the least VRF resistance among the gutta-percha based materials.

\section{Clinical Significance}

Obturation of the root canals with resin based obturation system-Resilon reinforces the fracture resistance of endodontically treated teeth and contributes to the overall success of the endodontic treatment.

\section{REFERENCES}

1. Pitts DL, Natkin E. Diagnosis and treatment of vertical root fractures. J Endod 1983;9(8):338-346.

2. Bender IB, Freedland JB. Adult root fracture. J Am Dent Assoc 1983;107(3):413-419.
3. Sjogren U, Hogglund B, Sundqvist G, Wing K. Factors affecting long term results of endodontic treatment. J Endod 1990;16(10): 498-504.

4. Vire DE. Failure of Endodontically treated teeth: classification and evaluation. J Endod 1991;17(7):338-342.

5. Johnson ME, Stewart GP, Nielsen CJ, Hatton JF Ill A, Minn M. Evaluation of root reinforcement of endodontically treated teeth. Oral Surg Oral Med Oral Pathol Oral Radiol Endod 2000;90(3): 360-364.

6. Helfer AR, Meinick S, Schilder H. Determination of moisture content of vital and pulpless teeth. Oral Surg Oral Med Oral Pathol 1972;34(4):661-670.

7. Trabert K, Caputo A, Abou-Rass M. Tooth fracture-A comparison of endodontic and restorative treatments. J Endod 1978;4(11):341-345.

8. Gutmann JL. The dentin — root complex: anatomic and biologic considerations in restoring endodontically treated teeth. J Prosth Dent 1992;67(4):458-467.

9. Trope M, Ray HL. Resistance to fracture of endodontically treated roots. Oral Surg Oral Med Oral Pathol 1992;73(1):99-102.

10. Pilo R, Corcino G, Tamse A. Residual dentin thickness in mandibular premolars prepared with hand and rotator instruments. J Endod 1998;24(6):401-404.

11. Onnink PA, Davis RD, Wayman BE. An in vitro comparison of incomplete root fractures associated with three obturation techniques. J Endod 1994;20(1):32-37.

12. Kishen A. Mechanisms and risk factors for fracture predilection in endodontically treated teeth. Endo Top 2006;13(1):57-83.

13. Lertchirakarn V, Palamara JEA, Messer HH. Load and strain during lateral condensation and vertical root fracture. J Endod 1999;25(2):99-104.

14. Saw LH, Messer HH. Root strains associated with different obturation techniques. J Endod 1995;21(6):314-320.

15. Sornkul E, Stannard JG. Strength of roots before and after endodontic treatment and restoration. J Endod 1992;18(9): 440-443.

16. Wu MK, Van Der Sluis LMW, Wesselink PR. Comparison of mandibular premolars and canines with respect to their resistance to vertical root fracture. J Dent 2004;32(4):265-268.

17. Tamse A. Vertical root fractures in endodontically treated teeth: diagnostic signs and clinical management. Endo Top 2006;13(1): 84-94.

18. Harvey TE, White JT, Leeb IJ. Lateral condensation stress in root canals. J Endod 1981;7(4):151-155.

19. Walton RE, Michelich RJ, Smith GN. The histopathogenesis of vertical root fractures. J Endod 1984;10(2):48-56.

20. Apicella MJ, Loushine RJ, West LA, Runyan DA. Comparison of root fracture resistance using two root canal sealers. Int Endod J 1999;32(5):376-380.

21. Tamse A, Lustig J, Kaplavi J. An evaluation of endodontically treated vertically fractured teeth. J Endod 1999;25(7):506-508.

22. Holcomb JQ, Pitts DL, Nicholls JI. Further investigating of spreader loads required to cause vertical root fracture during lateral condensation. J Endod 1987;13(6):277-284.

23. Monaghan P, Bajalcaliev JG, Kaminski EJ, Lautenschlager. A method for producing experimental simple vertical root fractures in dog teeth. J Endod 1993;19(10):512-515.

24. Wilcox LR, Roskelley C, Sutton T. The relationship of root canal enlargement to finger-spreader induced vertical root fracture. J Endod 1997;23(8):533-534. 
25. Bouillaguet S, Shaw L, Barthelemy J, Krejci I, Wataha JC. Long term sealing ability of pulp canal sealer, AH -Plus, GuttaFlow and Epiphany. Int Endod J 2008;41(3):219-226.

26. Shipper G, Texeira FB, Orstavik D, Trope M. An evaluation of microbial leakage in roots filled with a thermoplastic synthetic polymer-based root canal filling material (Resilon). J Endod 2004;30(5):342-347.

27. Skidmore LJ, Berzins DW, Bahcall JK. An in vitro comparison of the intraradicular dentin bond strength of resilon and guttapercha. J Endod 2006;32(10):963-966.
28. Teixeira FB, Teixeira ECN, Thomson JY, Trope M. Fracture resistance of endodontically treated teeth using a new resin filling material. J Am Dent Assoc 2004;135(5):646-652.

29. Hammad M, Qualtrough A, Silikas N. Effect of new obturating materials on vertical root fracture resistance of endodontically treated teeth. J Endod 2007;33(6):732-736.

30. Grande NM, Plotino G, Lavorgna L, Ioppolo P, Bedini R, Pameijer CH, Somma F. Influence of different root canal filling materials on the mechanical properties of root canal dentin. $\mathrm{J}$ Endod 2007;33(7):859-863. 